\title{
Challenging the politics of early intervention: Who's saving children and why?
}

\author{
Val Gillies, Rosalind Edwards, and Nicola Horsley, 2017 \\ Policy Press, Great Britain \\ ISBN 978-1447324102, pp. 201, paperback, NZD54.53
}

I

$\mathrm{n}$ announcing her ministerial line-up,

Jacinda Ardern, our new Prime Minister,

announced that "of course we support

early intervention. What we want to do is see if that is truly what the investment approach was doing" (New Zealand Herald, 2017). Note, the efficacy of early intervention is not a concern, rather the question of whether that is what is being done. Gillies, Edwards, and Horsley (2017), challenge the taken-for-granted assumption that early intervention in children's lives is ideal, and detail the confluence of science, policy and neoliberalism that has informed the booming early intervention industry in the United Kingdom. They detail both how we have come to see early intervention as pivotal, and the results of research into what social workers think about such interventions.

Gillies at al., problematise the idea that certain forms of parenting, particularly those associated with lower classes, have a biological impact on children; can literally shrink their brains. In examining the provenance of this idea they question the science, and the resultant policy. With reference to the past, they demonstrate that biologised accounts of poverty follow a depressingly similar trajectory to the spread of eugenicist ideas and ultimately serve to more firmly entrench the concepts of neoliberalism. It is important to note they are not saying that there are no negative outcomes from abuse and neglect, rather they are questioning the biologising of this relationship and the scope of the lens being applied.

Chapter One provides a summary of the aims of their book, referencing the now

(hopefully) infamous Perry (2002) brain scans that purport to show differences between a normal and a neglected child's three-year-old brain. Without pulling any punches, they assert that claims of links between Romanian orphan studies and the childhoods of children living in poverty "might well be examples of scientific bullshit" (p. 14).

In Chapter Two, they chart the development of the early intervention discourse back to the $19^{\text {th }}$ century and show the links between saving children and the interests of the state in creating a productive citizenry. Gillies et al., show that children are redefined as potential human capital with parents bearing responsibility for either actualising or squandering it. Such ideas make invisible the structural forces working against these families and form a powerful justification for state intervention.

Chapter Three details the more recent history in the United Kingdom with an examination of social investment, and what role prevention science has played in redefining parenting. They examine, and find wanting, "five key biologised assertions" (p. 48) that the science relies upon; critical periods of development, brain damage by "poor maternal attunement" (p. 51), the role of synaptic density, the damaging effects of cortisol, and the stunted brains of children who have been abused and/or neglected. This is the chapter I would recommend any social worker, or social work student reads, as it distils key concerns with the science into an easy to read summary with plenty of references to follow up if required. 
Policy making is the focus of Chapter Four, by looking at who is influencing this, and why. Gillies et al. deftly show how business is gaining a foothold in the social sector in the name of social investment and thereby gaining lucrative contracts via a government keen to find market solutions. They note that this field is full of philanthrocapitalists "powered by a conviction that an application of market methods can save the world" (p. 75). Such philanthrocapitalists then shape policy through extensive personal networking with a vision to save society (and thus children) through the use of the evidence they have gathered and the money they have available.

Chapter Five then builds on the previous chapter by providing three case studies of the sort of organisations that Gillies et al. are critiquing; the "Wave Trust," "Family Nurse Partnerships" and the "Parent Infant Partnership UK." Through these case studies they demonstrate the intricate links between business, personal agendas and policy, and how these are reinforcing a certain narrative about parenting, particularly mothering, that situates it as the solution to all social ills at the expense of larger structural concerns.

It is perhaps Chapter Six that may be of key interest to the current practice of social workers in Aotearoa New Zealand. Here Gillies et al. report on their research, interviewing social workers about how they utilise these sciences in everyday practice. They note that they found two key ideas implicit in practitioner judgements about whether to intervene or not; that such interventions would somehow optimise both mother and child(ren), and that problematic attachment and deficit parenting is intergenerational. These two assumptions then justify the belief that children need to be "saved." Their findings demonstrated that many practitioners had an almost religious zeal about their work, and that the science was seen as buttressing their practice. Ideas of saving the public money, alongside saving the children, permeated their thinking with little to no thought given to examining the truth of these ideas. Gillies et al. were careful to allow the practitioners plenty of opportunities to question this rhetoric, as is demonstrated in their article (Horsley, Gillies, \& Edwards, 2016); however, despite this, the practitioners interviewed did not demonstrate any awareness of the science being problematic.

Chapter Seven widens the lens and considers the structural issues that Gillies et al. consider to be absent in the discussion of early intervention. They demonstrate how this science-based policy differentially impacts on mothers, particularly those who are poor and/or are from ethnic minorities. They conclude that this use of science through policy "positions mothers as buffers" against wider concerns, and "asserts the effacement of social divisions at the same time as it embeds a range of inequalities" (p. 133). They also warn that with such discourses it is easy to conclude that inequalities become biologised, thus, "ethnic practices and racialized difference can become reified as biological difference rather than a socially designated and produced category" (p. 148). Such conclusions, relying on the concept of intergenerational transmission, can then lead to biologised conceptions about race and poverty that has eerie parallels with eugenics.

Fortunately, Gillies et al. conclude with a vision of what could be: they introduce an alternative vision, one that relies on a holistic view. They note that policy and practice need to centre poverty, not the individual family (or child). They add that this individualising, and even moralising discourse, allows us to ignore our collective responsibility, and that this ultimately, rather than serving those it should help, only really benefits the wealthy philanthrocapitalists.

In conclusion, this book provides an easyto-read analysis of the state of policy, practice, and the science underpinning both, within the children's services of the United 
Kingdom. Gillies et al. provide a wellreferenced examination of the field at both micro and macro levels. There are lessons to be learnt here for Aotearoa/New Zealand, by social workers (both future and present) and policy makers alike as conversations about social investment continue, prevention science is used in practice, and the influence of philanthrocapitalists in Aotearoa New Zealand, in policy and politics, increases.

Reviewed by Eileen Joy, PhD student, School of Counselling, Human Services \& Social Work, University of Auckland

\section{References}

Horsley, N., Gillies, V., \& Edwards, R. (2016). Researchers' reflections on interviewing policy makers and practitioners: Feeling conflicted in critical research. Paper presented at the Women's Studies International Forum, 1-14.

New Zealand Herald. (2017, October 25). Jacinda Ardern reveals ministers of new government. Retrieved from http://www.nzherald.co.nz/nz/news/article.cfm?c_ id=1\&objectid=11936599

Perry, B. D. (2002). Childhood experience and the expression of genetic potential: What childhood neglect tells us about nature and nurture. Brain and Mind, 3, 79-100. 